\title{
A Iniciação Científica como estratégia pedagógica para integrar ensino e serviço no SUS
}

\author{
Mateus Rodrigues Cunha*; Graciela Soares Fonsêca**; Maria Ercília de Araujo***; Celso \\ Zilbovicius $* * * *$ \\ * Estudante, voluntário de Iniciação Científica do \\ Departamento de Odontologia Social da FOUSP \\ ** Professora adjunta do Curso de Medicina da \\ Universidade Federal da Fronteira Sul, UFFS, \\ Campus Chapecó \\ *** Professora Titular da área de Saúde Coletiva no \\ Departamento de Odontologia Social da FOUSP \\ **** Professor da Disciplina de Ciências Sociais em Saúde \\ FOUSP
}

\section{RESUMO}

As atividades extramuros, tais como estágios supervisionados, disciplinas e atividades de ensino-extensão-pesquisa têm sido consideradas importantes na formação do cirurgião-dentista. O objetivo deste estudo é avaliar a Iniciação Científica (IC) no Sistema Único de Saúde (SUS) como estratégia de aprendizado extramuros e integração ensinoserviço. Para isso, um aluno de IC realizou um estudo qualitativo por meio de entrevistas, que investigou a percepção do gestor, usuários e servidores a respeito do sistema de saúde bucal no município de Carapicuíba/SP. A partir deste material foram elaboradas duas análises. A primeira foi uma Análise de Conteúdo, segundo proposto por Bardin, das entrevistas realizadas com usuários, servidores e gestor. A segunda, sobre a percepção do aluno quanto à experiência do trabalho realizado sem a presença do orientador. O estudante concluiu que a IC no ambiente do SUS possibilitou um diálogo crítico entre a realidade e o conteúdo teórico das legislações, regulamentações e da gestão de um sistema municipal de saúde bucal. Portanto, a IC é uma ferramenta rica para o aprendizado do SUS e para o desenvolvimento de habilidades do aluno de graduação, contribuindo para a formação de profissionais qualificados para atuar no sistema.

Descritores: Recursos Humanos em Saúde. Educação em Odontologia. Saúde Pública. Serviços de Integração Docente-Assistencial. Pesquisa sobre Serviços de Saúde.

\section{INTRODUÇÃO}

O Sistema Único de Saúde (SUS) é um sistema de saúde com a missão de atender a todas as pessoas (universalidade), de forma igual e sem discriminações (equidade) e o ser humano em todas as suas necessidades

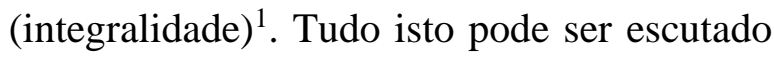
numa sala de aula na disciplina de saúde coletiva. Mas como é a realidade? Qual a opinião dos usuários? Como é praticar Odontologia num sistema municipal de saúde? Estas questões são muito importantes para um acadêmico, sendo o SUS um 
potencial campo para o exercício profissional $^{2,3}$.

O contato com o sistema se faz necessário haja visto o distanciamento deste com o modelo de atendimento das clínicas da universidade ${ }^{3}$. Para isso, tem-se mostrado a importância das atividades extramuros na formação do cirurgião-dentista (CD), incluindo-se estágios supervisionados, disciplinas e atividades de ensino-extensãopesquisa $^{4-7}$.

Segundo as Diretrizes Curriculares Nacionais do Curso de Graduação em Odontologia (DCN) de fevereiro de $2002^{8}$ " $A$ formação do cirurgião dentista deverá contemplar o sistema de saúde vigente no país (Resolução CES/CNE $n^{o} 03-D C N /$ Odontologia)".

Morita e Kriger (2004) $)^{3}$ destacam competências e habilidades necessárias para trabalhar no SUS e que precisarão ser revistas nas escolas de Odontologia, dentre elas pensar criticamente, tomar decisões, ser líder, planejar estrategicamente para contínuas mudanças, administrar e gerenciar serviços de saúde, atuar em equipes multiprofissionais. Também sugerem que os cursos de saúde, dentre outras coisas, precisam "Promover atividades práticas ao longo de todo o curso em todos os tipos de unidades de saúde". Propõem protocolos de cooperação entre os cursos, a ABENO, os Ministérios da Saúde e Educação e os gestores estaduais e municipais, de forma que o ensino deixe de ser centrado no professor, para atingir uma aprendizagem ativa desenvolvendo-se em múltiplos cenários. Cabe ao professor o papel de facilitador do processo de construção do conhecimento, caracterizando-se o aluno como o sujeito da aprendizagem.

Dentre as atividades práticas para integração ensino serviço existe a Iniciação Científica (IC). Em sua definição, a IC é um instrumento de apoio teórico e metodológico à realização de um projeto de pesquisa $\mathrm{e}$ constitui um canal adequado de auxílio para a formação de uma nova mentalidade no aluno. Em síntese, a IC pode ser definida como um instrumento de formação de recursos humanos qualificados ${ }^{9}$. A IC no SUS possibilita ao aluno contato com o serviço, gerando um diálogo crítico, entre o que é exposto nas aulas teóricas e a prática na realidade. Poderá levá-lo a ter contato direto sem a presença local de um tutor, sendo orientado à distância, permitindo o desenvolvimento de autonomia e o protagonismo do aluno no processo de aprendizagem ao estudar o sistema.

Este estudo propõe-se a investigar o caminho da IC no SUS como estratégia de formação e ferramenta de integração ensino e serviço. Para isso, foi analisado o percurso de um aluno da graduação que realizou um trabalho qualitativo sobre um sistema municipal de saúde bucal, intitulado "A atenção à saúde bucal em Carapicuíba/SP: análise institucional e percepção de usuários, servidores e gestor".

\section{METODOLOGIA}

O aluno da graduação decidiu realizar uma pesquisa sobre o SUS do município de Carapicuíba/SP, pois era um território que conhecia. Fez uma análise com levantamento de dados a partir de fontes oficiais. Depois escreveu um projeto de pesquisa qualitativa, intitulado: "A atenção à saúde bucal em Carapicuíba/SP: análise institucional e percepção de usuários, servidores e gestor". Em seguida, entrou em contato com a coordenadora de saúde bucal e realizou entrevistas com os dentistas de todas as dez Unidades Básicas de Saúde (UBS) e com usuários de oito delas (uma das UBS estava sem atendimento odontológico devido ao 
roubo do compressor), totalizando 13 dentistas e 14 usuários. As entrevistas foram gravadas, transcritas, lidas e organizadas em categorias.

As entrevistas foram estruturadas em questionários a fim de se investigar a percepção de usuários (que já estavam em tratamento), servidores (CD da rede pública) e gestor a respeito do sistema municipal de saúde bucal. Com este material foram construídas duas análises qualitativas.

A primeira foi elaborada tendo como referência a análise de conteúdo de $\operatorname{Bardin}^{10}$, para a análise e interpretação dos resultados. Assim, os resultados foram organizados em dois blocos de categorias. No primeiro bloco os conceitos e percepções dos CD sobre: 1) Acolhimento do profissional e capacitação para trabalhar no SUS, 2) Procedimentos Coletivos e 3) Política Nacional de Saúde Bucal. No segundo bloco, a percepção dos usuários (U) sobre: 1) Valorização da assistência e 2) Acessibilidade ao sistema. Ao fim de cada bloco é apresentada a visão da coordenadora de saúde bucal como forma de comparação.

A segunda análise foi sobre a percepção do aluno a partir da descrição da experiência de ter feito as entrevistas em contato com um sistema municipal do SUS sem a presença do orientador.

$\mathrm{O}$ projeto de pesquisa, incluindo o questionário das entrevistas, foi aprovado pela secretaria de saúde da cidade de Carapicuíba/SP e pelo Comitê de Ética em Pesquisa com Seres Humanos da Faculdade de Odontologia da Universidade de São Paulo (FOUSP), parecer CEP 1167897 e número do CAAE 43925615.3.0000.0075.

\section{RESULTADOS E DISCUSSÃO}

3.1 Análise qualitativa das entrevistas de CD e usuários
Acolhimento do profissional e capacitação para trabalhar no SUS

Chama a atenção o fato de os dentistas, em sua maioria, considerarem ter começado sua prática no serviço público sem receber do sistema uma capacitação, como explicitado nos recortes a seguir:

"Treinamento não, nós temos uma integração com a coordenadora de saúde, então, quando nós entramos, todos os concursados que passaram acabaram conhecendo quem já tava na rede, os mais antigos, e foi explicado como é o atendimento, aonde seria feito as especialidades, se existia especialidade, o que faríamos dentro da unidade. Mas não é um treinamento assim específico, não chega a ser um treinamento. “(CD 2)

"Bem pouca, assim, bem básica. Muito pouco, mas sim. Depois a gente vai aprendendo com o tempo filho. Com o tempo que você vai vendo né?" (CD 5)

Há os que consideram alguns encontros com a coordenadora de saúde bucal como capacitação.

" Foram 2 encontros né? Um com a outra coordenadora de saúde bucal e um com a atual. Que ela deu até uma pasta com vários materiais, orientação, tudo. Recebemos sim." (CD 4)

Do ponto de vista da atual coordenadora de saúde bucal ela tem incentivado que os dentistas estudem, mas não relata a realização de reuniões periódicas para avaliação do trabalho e capacitação dos servidores, por parte do sistema, com enfoque nas ações coletivas.

"É algo no qual estou preocupada em envolvê-los neste sentido, de procurar aprimorar o que eles fazem, conhecer novas áreas. Então, hoje nós temos alguns dentistas que fazem 
especialização. A gente da prefeitura tenta facilitar os horários para que eles consigam estudar. Estimulamos todos eles a participar de pelo menos um congresso anualmente. Então ele é liberado para participar deste congresso". (G)

Seria importante realizar capacitação e integração dos cirurgiões dentistas que ingressam no setor público. Isso possibilitaria um acolhimento do profissional e um conhecimento não apenas dos processos burocráticos (sistemas de referência, preenchimento de prontuários, relatórios, etc.), mas sobre o território e as características da população. Poderiam ser ensinados métodos de padronização de trabalho, como protocolos ${ }^{11}$ e dar orientação quanto a realizar ações coletivas, como levantamentos epidemiológicos e programas de exames preventivos. Encontros periódicos para se reunir a equipe odontológica de forma a escutar os profissionais e suas demandas, discutir os problemas e de forma conjunta avaliar as situações e buscar alternativas para a melhoraria dos serviços e consolidação da atenção à saúde bucal da população municipal.

Em relação à pergunta: "Como você avalia as condições do seu ambiente de trabalho, para o exercício da sua prática profissional? Se puder situar pontos positivos, pontos negativos..." um dentista afirmou:

"Ããa, o ponto negativo, eu citaria alguns, né, eu acho que não tem reuniões periódicas, eu particularmente não participei de nenhuma reunião até agora ããa... eu acho que o grande ponto negativo eu acho que é esse, eu acho que é falta de reuniões pra gente poder melhorar, pensar em algumas coisas em conjunto..." (CD 1)
Também realizar qualificação
periódica como forma de educação permanente. Poderiam ser ministradores alguns dos próprios dentistas da rede que têm especialização em Ortodontia, Ortopedia Funcional dos Maxilares, Odontopediatria, Implantodontia e mestrado em Anatomia e Saúde Pública.

\section{Procedimentos Coletivos}

Segundo Silva (1996) ${ }^{12}$ procedimentos coletivos são medidas tomadas visando não à instância particular de um dado indivíduo, mas um grupo de pessoas. Busca-se um efeito geral, global e impessoal, no mais das vezes preventivo, que procura impedir a ocorrência de um ou mais agravos e não a reversão de suas consequências. Dentre os procedimentos coletivos em saúde bucal estão a escovação dental supervisionada, bochecho fluoretado, exame bucal com finalidade epidemiológica, educação em saúde por profissional na comunidade, que inclusive até 2006 compunham a Tabela SAI-SUS ${ }^{13}$.

Percebe-se que muitos dentistas entendem procedimentos coletivos apenas como ações de prevenção em escolas ou a orientação de higiene bucal, mesmo que particular e em ambiente de consultório. Os recortes a seguir demonstram isso:

"Sim, a escovação... as técnicas de escovação, eu mostro pra eles individualmente depois como é que tem que fazer..." (CD 9)

Chega a fazer alguma coisa juntando mais o pessoal? Tipo uma palestra que junta mais gente?

"Agora não. Mas talvez a gente chegue a fazer. E se for uma coisa viável." (CD 9)

Ok. Tem sido mais aqui no consultório? Isso, a técnica de escovação a gente tem feito também." (CD 9) 
$\mathrm{Na}$ realidade nem as ações de prevenção, que costumam ser feitas fora da UBS, em outros espaços, os dentistas têm realizado. Sua atividade está centrada no atendimento individual dos pacientes dentro do consultório:

"Não, em escola eu não vou." (CD 11) Você realiza procedimentos coletivos? "De prevenção? É, hoje a gente faz uma parte de escovação, de orientação... Mais com o paciente aqui dentro do consultório. Mas eu já fiz muita palestra, a parte de prevenção. Tem uma equipe que faz a parte de prevenção nas escolas. Aqui é mais direto com o paciente." (CD 3)

Alguns afirmam que raramente realizam procedimentos coletivos e outros tem a percepção de que ações coletivas incluem também exames preventivos.

"Coletivos não. Porque aqui o atendimento é individual. A gente só faz...é fizemos uma vez uma palestra... é um procedimento coletivo" (CD 4)

"É mas não é assim direto. Nós fizemos uma vez só e um exame." (CD 13)

" $E$ a gente conversa mais assim direto com o paciente, pra fazer orientação de escovação estas coisas. Coletivo assim com palestra..." (CD 4)

"Sim, nas campanhas que a gente tem aqui no posto a gente faz programas de saúde bucal por aqui. Eu participei agora, né recentemente da campanha de vacinação que a gente fez análise de lesões bucais em pacientes com mais de 50 anos, sobre risco do câncer bucal. Sempre tem [campanhas] é que eu não peguei muitos mas existe, como eu não to nem um ano aqui eu não peguei muitas. Mas sempre tem." (CD 10)

Segundo a coordenadora de saúde bucal, o município conta com uma equipe de prevenção em saúde bucal. Esta equipe realiza ações de prevenção como higiene bucal supervisionada, evidenciação de placa, aplicação de flúor e palestras na rede escolar municipal. Também realizam levantamentos epidemiológicos que começaram a ser feitos em 2014, não havendo disponíveis dados anteriores a este período.

"Nós temos 5 dentistas que trabalham só com prevenção. Nas escolas. Nas EMEF's, EMEI's e creches. Todas as escolas municipalizadas. Elas fazem palestra, escovação supervisionada. A gente tenta sempre fornecer escova de dente, evidencicador de placa. Nas EMEF's em crianças maiores de 7 anos [os dentistas fazem aplicação de flúor]. SIM, existe [planejamento local de saúde bucal baseado em dados epidemiológicos] eu estou na coordenação há menos de 2 anos, então assim que eu entrei eu fiz um levantamento epidemiológico nas crianças matriculadas nas EMEIS e EMEF'S pra saber qual que era a necessidade do município neste sentido. Não tive acesso [a dados epidemiológicos anteriores a atual gestão].” (G)

O sistema conta com uma equipe de dentistas que é exclusiva para ações de prevenção, o que parece deixar os procedimentos coletivos para esta equipe e realocar os demais dentistas para atendimento clínico ambulatorial. Desta forma cria-se um distanciamento dos profissionais em relação ao território e de se procurar estratégias intersetoriais para se consolidar a atenção à saúde bucal. Existe, por tanto, uma limitação dos procedimentos coletivos à população da rede escolar municipal excluindo-se jovens, adultos e idosos, além de alunos que frequentam escolas do Estado ou da rede 
particular.

\section{Política Nacional de Saúde Bucal}

Nota-se um desconhecimento sobre a Política Nacional de Saúde Bucal ${ }^{14}$, principalmente dos dentistas mais antigos na rede. Os que ingressaram mais recentemente afirmam conhecê-la em geral porque tiveram que estudá-la por ser conteúdo do concurso público de admissão.

As falas a seguir exemplificam esse achado: “Aí... eh.. Já! Já li por cima.” (CD 11)

"Sim, pelo estudo né? Pra fazer a prova... " (CD 10)

"....conheço... (expressão facial de dúvida)" (CD 12)

"Não, não digo completa, mas o básico né? O que se faz numa unidade básica de saúde sim." (CD 7)

"Política.... São aqueles 9... aqueles itens? É.. não sei te dizer... é melhor eu falar que eu não me lembro." (CD 6)

"Mais ou menos. Alguma coisa." (CD 5)

Este configura-se como mais um desafio para a consolidação da atenção à saúde bucal. Parece não haver necessidade de se conhecer a Política Nacional de Saúde Bucal, pois, afinal o que ela mudará na rotina do serviço? Ele continuará focado em ações de assistência à saúde, com poucas ações de prevenção e promoção. $\mathrm{O}$ sistema poderia ter ações de formação continuada e esclarecer e informar sobre a Política Nacional de Saúde Bucal e demais portarias e atualizações. Estas serviriam de base para reuniões mensais onde os serviços seriam avaliados e propostas melhorias.

\section{Valorização da assistência}

A maioria dos usuários avalia bem o atendimento que recebeu do cirurgião dentista.

"Bom, o meu eu achei que foi perfeito". (U1)

"Ta 100\%. Ta bastante bom". (U 2)

"A dentista me tratou super bem". (U 3)

"Eu gostei né? Ela me deixou segura. Eu gostei." (U 10)

Alguns fazem críticas ao atendimento, mas não voltadas ao relacionamento pacienteprofissional, geralmente estão relacionadas com entraves em se acessar o sistema ou em concluir o tratamento.

"Olha, eles me atenderam bem. Só mesmo foi o problema que eu precisei arrancar o dente na época e não tive resultado. Não arrancaram. Porque só tavam atendendo mesmo as gestantes e emergência". (U 4)

"Aqui foi péssimo. No dia que eu recebi foi péssimo [...] atendeu direitinho, só que ele foi mandado embora e não terminou o serviço. (U 6)

Ah! Entendi, mas a parte DELE... [dentista]

$O$ atendimento foi ótimo, só que foi mandado embora e não terminou o serviço. Ai eu fui e paguei" (U 6)

É interessante a percepção que os próprios dentistas têm da população.

"Ah, a população aqui é carente né? Muita carência. Então, assim, então, coitados, não sabem nem avaliar. $O$ que você oferecer... [está bom] " (CD 12)

É notável a homogeneidade da população em toda a cidade, por isso as respostas acabam se repetindo, não sendo encontradas diferenças nos discursos entre as UBS.

“...com a comunidade o pessoal é fácil de lidar. Se vê que a diferença é muito pouca (risos). $O$ outro posto eu trabalhei 14 anos né? “ (CD 8) 


\section{Acesso}

As principais críticas dos usuários ao sistema de saúde bucal são direcionadas à dificuldade de acesso principalmente relacionada à demora de se conseguir atendimento nas UBS's e nas referências para os CEO's.

"Aí depois a prótese eu fiz particular né? Porque ela podia até encaminhar [para o CEO] mas demorava muito." (U 11)

"Ah, médio né? [atendimento recebido do dentista] Não pode ser ótimo, porque... num é né? Mas o tratamento foi médio." (U 11)

Que que a senhora acha que foi bom e o que que não foi ou podia melhorar?

"Ah, um atendimento mais rápido, porque as vezes você precisa tratar logo. Aí, você tem que esperar um ano! Muito tempo." (U 11)

Mas quando chegou o momento do atendimento, na hora com a dentista...

“Não, ai ela foi bem... né?" (U 11)

Então o problema é a demora então?

"É a demora. Porque eu acho que tinha que ser mais rápido. A gente vinha aqui hoje e marcava e no mês que vem já tratava né? Mas não. Fica na fila de espera. Quando eu vim, meu dente não tava tão ruim. Aí quando eu cheguei pra tratar já tinha quebrado. Aí eu falei pra ela, então arranca tudo. Aí ela falou: "não. Só vou tirar este que está quebrado e não tem jeito e os outros a gente vai fazer canal, vai fazer obturação. " (U 11)

"Agora... o problema eu acho que é difícil encaixar né? Mas eu consegui, consegui encaixar. É muita gente que interessa né? É pouca vaga. É isso que é o problema. ” (U 7)

Alguns usuários identificam a falta de acesso a algumas especialidades.

Quais são os serviços que você precisa? [que não tem na UBS]

“Aparelho. Estética." (U 3)

Além de uma demanda reprimida alta e baixa arrecadação municipal de impostos existe uma exclusão da população economicamente ativa. Os horários de atendimento das UBS ocorrem em geral das $7 \mathrm{~h}$ às $17 \mathrm{~h}$. Desta forma, além de haver uma espera longa para se conseguir a consulta ela ocorre num horário não possível para os que trabalham. Aliado a isso o fato de a população não ter costume de buscar o serviço preventivamente, ocorrem muitos casos de urgência. Não é raro quando todos os casos de urgência não podem ser resolvidos e é neste momento que aparecem as maiores críticas dos usurários ao sistema de saúde bucal. Todos os dentistas precisam ocupar parte dos seus turnos atendendo urgências.

"Porque na época eu vim atrás só tava atendendo gestante mesmo. Aí voltei de novo e só fizeram o que eu não pude fazer. [..] Por que tavam atendendo [só 1 gestante. E emergência." (U 4)

Os dentistas apontam problemas que geram dificuldade de acesso como a enorme demanda em relação ao número de dentistas.

"Olha [da] população tem um retorno bom [...] Mas a população é boa, o único problema é assim, a demanda é muito grande, pra pouco dentista. Né? Que nem, aqui atende 10 bairros. Então assim, tem uma lista de espera né, a gente vai chamando assim, conforme o pessoal pede, mas assim, eu acho que a demanda é muito grande, um ponto negativo é uma demanda muito grande pra pouco dentista”. (CD 5)

Segundo a coordenadora de saúde bucal a cidade tem poucos recursos públicos, uma população grande e muitas pessoas que 
tratam a saúde bucal no SUS, além de uma demanda reprimida histórica.

"Uma cidade dormitório, uma cidade pobre. O número de dependentes SUS é muito alto. Com uma arrecadação muito baixa. " $(\mathrm{G})$

Qual a cobertura em termos da população municipal dos serviços oferecidos? Tem ideia de quanto da população consegue ser atendida?

"Eu não teria este dado especifico pra te passar. Principalmente por ser uma população $90 \%$ pelo que dizem depende do SUS. Então é uma demanda muito grande em todas as áreas. Tem uma demanda reprimida de anos e décadas e hoje quando abriu o serviço a gente percebe. " (G)

Estas dificuldades são comuns nos municípios de pequeno porte como descritas por Cecílio et al. $(2007)^{15}$.

Dentre os problemas para a demora no atendimento se destaca os repetidos roubos de compressor de uma UBS.

"Esta unidade que estou te mostrando, está com problema, pois está sem o compressor, por isso você pode ver que a produtividade está baixa. Roubaram o compressor pela quarta vez. Só este ano é a segunda vez." (G)

Alguns dentistas apontaram a queda dos atendimentos por falta de materiais relacionada a problemas com uma licitação recente.

“...Há duas semanas você tem que dispensar paciente em tratamento porque não tem material esterilizado, então eu acho que isso tá pegando, momentaneamente tá pegando, mas eu acho que é uma coisa transitória, a secretaria de saúde fez até uma reunião com a gente, tal, falou que teve problema mesmo na licitação..." (CD 4)
Houve uma diminuição temporária de recebimento de recursos pela queda da produção do CEO que ocorreu pela recomposição do quadro de dentistas.

"Inclusive nós estamos com problemas no CEO, pois os dentistas eram contratados, eles foram demitidos e foi realizado concurso. Então caiu muito a produção, perdeu-se financiamento $e$ agora tá tentando recuperar a produção pra recuperar também o financiamento." $(\mathrm{G})$

Existem projetos baseados nos dados epidemiológicos levantados recentemente pela coordenadora de saúde bucal.

"Estou na coordenação há menos de 2 anos então assim que eu entrei eu fiz um levantamento epidemiológico nas crianças matriculadas nas EMEIS e EMEF'S pra saber qual que era a necessidade do município neste sentido" $(\mathrm{G})$

"As dentistas [da equipe e prevenção] realizam só trabalho de prevenção dentro das escolas e a partir daquele levantamento epidemiológico que nós realizamos no final de 2014 nós descobrimos que temos muitas crianças com primeiro molar já comprometido. Então nós elaboramos um projeto chamado "Salvando meu primeiro molar permanente”. Então em agosto de 2015 nós vamos começar com uma escola piloto, onde nós vamos realizar ART nos dentinhos decíduos e no molar permanente ele vai como urgência pra UBS restaurar. Ele vai ter prioridade absoluta de restaurar este molar na UBS." (G)

"A gente está montando dentro do Projeto Cegonha, que é pra gestantes dentro da Rede Cegonha. A gente está montando um trabalho de inserir o 
dentista para participar desta rede cegonha" (G)

"a odonto assumiu o Programa Saúde na Escola do Ministério da Saúde” (G)

3.2 A iniciação científica como veículo para potencializar a integração da universidade com os serviços

Os primeiros tópicos desse manuscrito revelaram a trajetória investigativa e os achados encontrados por um estudante de graduação que se propôs a desenvolver um projeto de pesquisa de IC de modo articulado aos serviços de saúde, em um município de interesse para o aluno, como forma de responder aos anseios surgidos ao longo do seu processo de formação.

O principal objetivo dos programas de IC é introduzir o graduando no mundo da pesquisa $^{16}$, favorecendo uma formação ampliada além de possibilitar maior compreensão dos futuros cenários de trabalho, uma vez que permite a interação entre as atividades científicas e práticas da profissão ${ }^{17}$.

$\mathrm{Na}$ esfera do presente estudo, tornouse explícito que a imersão do estudante nas unidades de saúde, bem como o contato dele com profissionais e usuários dos serviços revelaram novas nuances para compreensão de aspectos ligados à organização política e de gestão do SUS, em consonância com o entendimento mais claro do papel da saúde bucal nos serviços públicos.

O estudante (E) redigiu uma narrativa reflexiva sobre seu processo investigativo. Destaca-se, a seguir, fragmentos que ilustram os benefícios oriundos das atividades de IC desenvolvidas:

"Foi bom realizar este trabalho. Pude conhecer o funcionamento de todo o sistema de saúde bucal de uma cidade. Conheci pessoalmente os dentistas, os consultórios e as UBS em funcio- namento." (E)

$\mathrm{O}$ estudante frisa o desenvolvimento de habilidade de comunicação, organização, planejamento e gestão - essenciais para o desenvolvimento do trabalho em saúde como consequência do desenvolvimento da sua pesquisa.

"Tive oportunidade de desenvolver habilidades de comunicação, organização e planejamento. Aprender a lidar com a parte burocrática de realizar uma pesquisa no âmbito do SUS tendo que me reportar a Secretaria da Saúde, coordenação de saúde bucal, gestores de UBS; redigir carta de intenções e carta de autorização. Também dialogar com autoridades, funcionários e usuários, com diferentes níveis de escolaridade e formação. Programar as visitas a todas às UBS dentro de seus horários de serviço odontológico no tempo hábil de férias que eu dispunha." (E)

Com maior riqueza de detalhes, o estudante coloca os benefícios trazidos por meio da aproximação com a realidade de trabalho do cirurgião-dentista no SUS, evidenciando, ainda, as discrepâncias existentes entre a formação propiciada pelas clínicas da instituição de ensino à qual se encontra vinculado e a realidade dos serviços de saúde.

"Creio ser de grande valia ter entrevistado os dentistas $e$ ter conhecido seu local e condições de trabalho. Atualmente o emprego público em UBS tem sido muito visado principalmente para os recémformados, porém apresenta-se como uma realidade desconhecida para os que só tiveram contato com a clínica da faculdade ou realizaram estágio em consultórios particulares. Mesmo eu, 
vindo da clínica da FOUSP que está inserida no serviço municipal como $C E O$, avalio que a dinâmica da clínica da UBS é bem diversa. Me deparei com boa infraestrutura e a presença de ASB em todos os consultórios. Os equipos são novos e os consultórios possuem espaço adequado para o atendimento. As consultas precisam ser rápidas e há que se aprender a lidar com os pacientes da fila da urgência que muitas vezes não podem ser todos atendidos. Também pude conhecer as falhas $e$ limitações. No período das visitas havia falta de anestésicos e agulhas por um erro no processo de licitação, o que limitava muito as possibilidades de atendimentos." (E)

O encontro com os serviços de saúde reais, com seus problemas, dilemas, tecnologias, dispositivos e políticas viabiliza a experienciação da realidade das condições de atenção e assistência à população ao passo em que também desperta o desejo de invenção e de reinvenção das rotinas de trabalho e das práticas cotidianas ${ }^{18}$.

\section{CONCLUSÕES}

Projetos de IC no SUS estimulam alunos a conhecer, de forma autônoma, a realidade de necessidades de saúde de grande parte da população bem como, sistemas de trabalho que se configuram cada vez mais numa importante opção para graduados.

Esta prática reforça a integração ensino-serviço configurando-se numa rede formativa que contempla as Diretrizes Curriculares Nacionais, bem como propõe a formação de profissionais voltados às necessidades de saúde da população brasileira.

\section{AGRADECIMENTOS}

Secretaria Municipal de Saúde e Medicina Preventiva da Prefeitura de Carapicuíba/SP.

\section{ABSTRACT \\ The Scientific Initiation as a pedagogical strategy for education and service integration in the SUS}

Extramural activities in the Dental undergraduate course have been shown as a very important and include supervised internships, and teaching-research-extension work. The aim of this study was to evaluate the scientific initiation (SI) in the Brazilian Public Health System (Sistema Único de Saúde, SUS) as extramural learning strategy and integration between education and service. Using interviews, a SI student conducted a qualitative study that investigated the perception of managers, users and servers about the public oral health system of the city of Carapicuíba/SP. Two analyzes were prepared with this material. The first one was a Bardin's content analysis, from interviews with users, servers and manager. The second one was the student's perception regarding the experience without the presence of the advisor. The student concluded that SI in SUS environment enabled a critical dialogue between reality and the theoretical content of the laws, regulations and management of a municipal system of oral health. Therefore, the SI is a rich tool for learning the public health system and for the development of undergraduate student skills, contributing to the training of qualified professionals to work in the system.

DESCRIPTORS: Health Manpower. Education Dental. Public Health. Teaching Care Integration Services. Health Services Research.

\section{REFERÊNCIAS}

1. Brasil. Constituição 1988. Art. 198 da Constituição da República Federativa do Brasil. Brasília (DF): Senado; 1988. 
2. Morita MC, Haddad AE, Araújo ME. Perfil atual e tendências do cirurgiãodentista brasileiro. 1a ed. Maringá: Dental Press; 2010.

3. Morita MC, Kriger L. Mudanças nos cursos de Odontologia e a interação com o SUS. Rev ABENO. 2004;4(1):17-21.

4. Cardoso AC, Corralo DJ, Krahl M, Alves LP. O estimulo à prática da interdisciplinaridade e do multiprofissionalismo: a Extensão Universitária como uma estratégia para a educação interprofissional. Rev ABENO. 2015;15(2):12-9.

5. Rodrigues CAQ, Costa SM, Leite MT; Mendes DC, Neto JFR. A vivência dos estudantes de odontologia nas atividades de ensino-pesquisa-extensão do PETSaúde. Rev ABENO. 2011;11(2):12-9.

6. Liberalino FN, de Andrade RCA, Araújo MD, Costa NDL, Almeida Jr JJ, Fernandes JD, et al PESC - projeto educação, saúde e cidadania: experiência extra-muros da UFRN, articulando e construindo saberes e ações entre academia, serviços de saúde e comunidade. PSICOLOGIA. 20:11 [Acesso em: 23/01/2015] Disponível em: www.prac.ufpb.br/anais/sempe/vsempean ais/Anais/saude/pesc.doc

7. Leme PAT, Pereira AC, Meneghim MC, Mialhe FL. Perspectivas de graduandos em odontologia acerca das experiências na atenção básica para sua formação em saúde. Cien Saude Colet. 2015;20(4) :1255-65.

8. Brasil. Conselho Nacional de Educação. Câmara de Educação superior. Resolução CNE/CES No 3, de 19 de fevereiro de 2002. Institui Diretrizes Curriculares Nacionais do Curso de Graduação em Odontologia. Brasil: CNE/CES; 2002.

9. Faculdade de Educação da Universidade
Federal de Goiás [homepage]. Goiânia: Universidade Federal de Goiás; 2015. Pedagogia - Iniciação científica e bolsa de iniciação científica. [Acesso em: 21/01/2015] Disponível em: https://www. fe.ufg.br/n/130-pedagogia-iniciacao-cien tifica-e-bolsa-de-iniciacao-cientifica.

10. BARDIN, L. Análise de Conteúdo. $3^{\mathrm{a}}$ ed. Lisboa: Edições 70; 2004.

11. Spedo SM, Pinto NRS, Tanaka OY. O difícil acesso a serviços de média complexidade do SUS: o caso da cidade de São Paulo, Brasil. Physis. 2010;20(3):953-72.

12. Silva LJ. Da vacina à aspirina: considerações acerca das ações coletivas em saúde pública. Saúde Soc.1996;5(2)316.

13. Carvalho LAC, Scabar LF, Souza DS, Narvai PC. Procedimentos Coletivos de Saúde Bucal: gênese, apogeu e ocaso. Saúde Soc. 2009;18(3)490-9.

14. Brasil. Ministério da Saúde/ Secretaria de Atenção à Saúde. Diretrizes da Política Nacional de Saúde Bucal. Brasília, 2004. [Acesso em: 21/01/2015] Disponível em: http://bvsms.saude.gov.br/bvs/publicacoe s/politica_nacional_brasil_sorridente.pdf

15. Cecílio LCO, Andreazza R, de Souza LM, Lima AMR, Mercadante CEB, Pinto NRS, et al. O gestor municipal na atual etapa de implantação do SUS: características e desafios. RECIIS. 2007; 1(2):200-7.

16. Conselho Nacional de Desenvolvimento Científico e Tecnológico- CNPq. O CNPq. [Acesso em: 03/11/2015] Disponível em: http://www.cnpq.br/ cnpq/index.htm

17. Erdmann AL, Leite JL, Nascimento KC, Lanzoni GMM. Vislumbrando a iniciação científica a partir das orientadoras de bolsistas da Enfermagem. Rev Bras Enferm. 2011;64(2)261-7.

18. Capozzolo AA, Casetto SJ, Henz AO. 
Clínica comum: itinerários de uma

formação em saúde. São Paulo: Hucitec;

2013. p.151-162.

Correspondência para:

Mateus Rodrigues Cunha

e-mail: mateusrodriguescunha@gmail.com

Rua Coronel Juliano, 257

04782-100 São Paulo, SP 